\title{
Control of Urea SCR Systems for US Diesel Applications
}

\author{
M. van Nieuwstadt and D. Upadhyay \\ Ford Motor Company, Dearborn, MI 48121 - USA \\ e-mail: mvannie1@ford.com - dupdhya@ford.com
}

\begin{abstract}
Résumé - Commande des systèmes de RCS à l'urée destinés aux applications Diesel US - Cet article a pour objet de qualifier les défis en matière de commande des systèmes de réduction catalytique sélective (RCS) dans une solution à base d'urée, pour la conversion des $\mathrm{NO}_{x}$ au sein de groupes motopropulseurs Diesel. Nous montrons l'importance de la maîtrise du stockage d'ammoniac ainsi que les difficultés à l'estimer face aux incertitudes du système. Les dynamiques de stockage lentes du catalyseur de RCS s'avèrent constituer un facteur de limitation majeur quant aux performances des systèmes de RCS au cours d'un fonctionnement transitoire. Enfin, nous montrons l'effet de l'incertitude des capteurs sur les performances du système et comment les capteurs de $\mathrm{NO}_{x}$ peuvent être utilisés en association avec une corrélation d'entrée pour distinguer une déviation de $\mathrm{NO}_{x}$ d'un glissement d'ammoniac.
\end{abstract}

\begin{abstract}
Control of Urea SCR Systems for US Diesel Applications - This paper sets out to qualify challenges in the control of urea selective catalytic reduction systems for $\mathrm{NO}_{x}$ conversion in Diesel powertrains. We show the importance of ammonia storage control, and the difficulties in estimating it in the face of system uncertainties. The slow storage dynamics of the SCR catalyst are shown to be a major limiting factor on the performance of SCR systems in transient operation. Lastly we show the effect of sensor uncertainty on system performance and how $\mathrm{NO}_{x}$ sensors can be used in conjunction with input correlation to distinguish $\mathrm{NO}_{x}$ slip from ammonia slip.
\end{abstract}




\section{INTRODUCTION}

This paper gives an overview of issues in the control of urea based Selective Catalytic Reduction (SCR) systems, with a focus on issues encountered in US Diesel powertrains. Since the issues are rooted in physical phenomena, many of the issues are not unique to US applications. Since US emissions standards are more stringent than the standards in other parts of the world, and since aftertreatment layouts for US trucks pose more challenges than light duty aftertreatment layouts, these issues pose a bigger challenge for US applications.

The emission standards imposed by 2010 US legislation force the use of $\mathrm{NO}_{x}$ aftertreatment on the vast majority of US diesel applications. Some applications employ lean $\mathrm{NO}_{x}$ traps. Lean $\mathrm{NO}_{x}$ traps can work for light duty passenger vehicles, such as the VW Jetta (Jetta, 2009), and applications certified against a higher TP standard such as the Dodge Ram. Lean $\mathrm{NO}_{x}$ traps struggle to achieve good $\mathrm{NO}_{x}$ conversion on high temperature cycles, such as the US heavy duty transient cycle. For these reasons, US diesel powertrains predominantly use urea SCR for $\mathrm{NO}_{x}$ aftertreatment. Products that are currently available include the Mercedes GL320, the BMW 335d, and the Audi Q7. In 2010 Ford, GM and Chrysler are expected to come out with SCR applications on their diesel trucks, certified against ULEV 2 standards.

\section{$1.1 \mathrm{NO}_{x}$ Emission Standards}

2010 US emissions legislation comprises a drastic reduction in tailpipe $\mathrm{NO}_{x}$ emissions. While the 2007 heavy duty standard allowed $1.2 \mathrm{~g} / \mathrm{bhphr}$, the 2010 standard only allows $0.2 \mathrm{~g} / \mathrm{bhphr}$. The light duty standard goes from tier 2 bin 8 $(0.2 \mathrm{~g} / \mathrm{m})$ to tier 2 bin $5(0.05 \mathrm{~g} / \mathrm{m})$, see (EPA, 2009). While the emissions standards are not expected to be tightened further in 2013, the OBD threshold multiplier will be reduced to values around $2 x$ to $3 x$ depending on the exhaust species.

\subsection{Organization of the Paper}

The paper will start with an overview of the components used in urea SCR systems, the exhaust configuration, the basic chemistry, and issues associated with the components. We will then proceed to the main focus of this paper, which is an evaluation of what are the hard and easy problems in the control of urea SCR systems. We use a two brick SCR configuration to illustrate the various points. We discuss the importance of ammonia storage, its control, and observers for ammonia storage. We quantify the effect of uncertainty on the performance of ammonia storage observers. In the last section we discuss $\mathrm{NO}_{x}$ sensors and how they can be used to trade off $\mathrm{NO}_{x}$ conversion against ammonia slip for 2010 diesel applications.

\section{BASICS OF THE SELECTIVE CATALYTIC REDUCTION SYSTEM}

\subsection{Exhaust Layouts}

A typical diesel aftertreatment system to meet 2010 US emissions standards consists of a Diesel Oxidation Catalyst (DOC), a Diesel Particulate Filter (DPF) and a $\mathrm{NO}_{x}$ catalyst. The latter can be a lean $\mathrm{NO}_{x}$ trap, or a urea SCR catalyst. In this paper we focus uniquely on the SCR. The DOC, DPF, and SCR can be combined in a variety exhaust system configurations. The DOC is usually first, to allow heating of the aftertreatment system, in startup, and for DPF regeneration. The SCR can be second, or last in the exhaust system. Both layouts have advantages for different applications.

Putting the SCR before the DPF (Fig. 1) allows a quicker light-off for the same fuel economy penalty, or the same light-off time with a lower fuel penalty. This is of importance for cycles that are heavily weighted toward cold start, such as the federal transient EPA75 light duty cycle. It is of less importance for cycles that are more heavily weighted toward hot start, such as the federal heavy duty transient cycle. Quick light-off is also of more importance for US truck applications, where the aftertreatment system is typically mounted underbody, far away from, the engine, which makes it harder to get heat into the aftertreatment system.

Putting the SCR after the DPF (Fig. 2) makes the system harder to light off, but it offers the advantage that the SCR will not be contaminated with soot, and that the DPF will to some degree be regenerated by the higher $\mathrm{NO}_{2}$ concentrations in the feed gas into the DPF. This also has the disadvantage of decreasing the $\mathrm{NO}_{2}$ available for the fast SCR reaction that relies on equal proportions of $\mathrm{NO}$ and $\mathrm{NO}_{2}$ to be present in the feedgas, Equation (2).

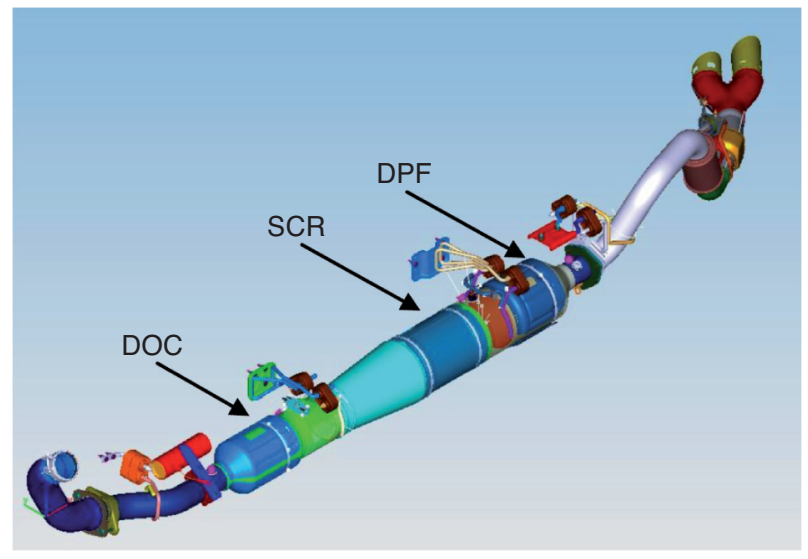

Figure 1

Light duty diesel exhaust layout. 


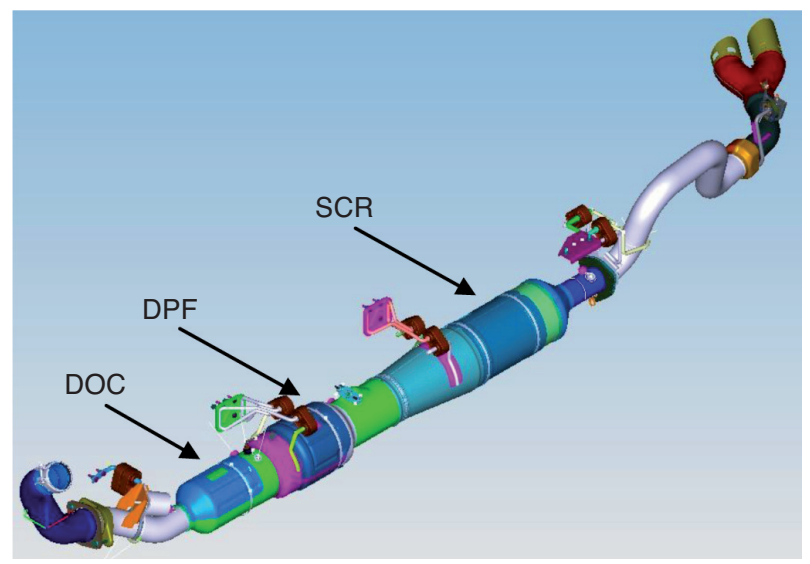

Figure 2

Heavy duty diesel exhaust layout.

\subsection{Ammonia Source}

The urea SCR catalyst needs ammonia $\left(\mathrm{NH}_{3}\right)$ to convert $\mathrm{NO}_{x}$. The source of ammonia can be liquid or solid. All systems currently in high volume production use a solution of aqueous urea as their ammonia source. A eutectic urea solution consists of $33 \%$ urea and $67 \%$ water. The advantage of a liquid ammonia source is that it is easy to handle. Two disadvantages are a poor $\mathrm{NH}_{3}$ to mass ratio, and a risk of urea deposit formation in the exhaust system.

Among solid ammonia sources are ammonia carbamate pellets, described in great detail by Fulks (2009). Another solution is proposed by Amminex, and stores $\mathrm{NH}_{3}$ in a strontium chloride salt. The ammonia is released from the solid by heating, and transported to the exhaust pipes in the gas phase. Solid ammonia sources typically have an $\mathrm{NH}_{3}$ to mass ratio 3 times better than liquid ammonia sources. Problems with solid ammonia sources are the transport to the exhaust gas, and the dosing accuracy. Dosing accuracy is important in adaptive control strategies that try to adjust ammonia supply to optimize a $\mathrm{NO}_{x}$ conversion- ammonia slip trade-off.

The urea in the aqueous urea solution is hydrolyzed to ammonia as follows:

$$
\begin{aligned}
& \mathrm{CO}\left(\mathrm{NH}_{2}\right)_{2}+\text { heat }=>\mathrm{HNCO}+\mathrm{NH}_{3} \\
& \mathrm{HNCO}+\mathrm{H}_{2} \mathrm{O}+\text { heat }=>\mathrm{NH}_{3}+\mathrm{CO}_{2}
\end{aligned}
$$

This requires heat and possibly mixing of the exhaust gas. In systems that are thermally challenged, there is a substantial risk that not all urea is hydrolyzed to ammonia, and forms deposits in the exhaust system. Once deposit formation has started, subsequent deposits are formed at an accelerated rate, due to the thermal insulation of metal exhaust parts by the urea layer. The urea deposits can be removed by exposure to heat, such as occurs during DPF regeneration. Since it is hard to model the rate of urea deposit formation, and removal by regeneration imposes a fuel economy penalty, it is best to prevent the deposit formation all together, by limiting the urea injection for cold exhaust temperatures. Directionally, urea injection is started around $180^{\circ} \mathrm{C}$, and limited to avoid deposit formation up to about $250^{\circ} \mathrm{C}$.

\section{3 $\mathrm{NO}_{x}$ Conversion}

The ammonia reacts with $\mathrm{NO}_{x}$ via a multitude of reactions steps, the most important reactions are:

$$
\begin{aligned}
& 4 \mathrm{NH}_{3}+4 \mathrm{NO}+\mathrm{O}_{2} \rightarrow 4 \mathrm{~N}_{2}+6 \mathrm{H}_{2} \mathrm{O} \\
& 2 \mathrm{NH}_{3}+\mathrm{NO}+\mathrm{NO}_{2} \rightarrow 2 \mathrm{~N}_{2}+3 \mathrm{H}_{2} \mathrm{O} \\
& 8 \mathrm{NH}_{3}+6 \mathrm{NO}_{2} \rightarrow 7 \mathrm{~N}_{2}+12 \mathrm{H}_{2} \mathrm{O}
\end{aligned}
$$

The first reaction is called the standard reaction, and is predominant specifically for low cost DOC formulations that do not generate much $\mathrm{NO}_{2}$, and at low temperatures. While some manufacturers design their aftertreatment system to rely on the $\mathrm{NO}_{2}$ in the feedgas to the SCR, we will assume here that the $\mathrm{NO}_{2}$ concentration is low, and that the standard reaction is dominant. The second reaction is called the fast reaction since its reaction rate is the highest. The third reaction is of theoretical interest in automotive applications, since the fast reaction takes out all $\mathrm{NO}_{2}$.

The DOC that is typically first in the exhaust system has the side effect of converting some $\mathrm{NO}$ to $\mathrm{NO}_{2}$, hence enhancing the fast reaction. This reaction is difficult to model in the face of different oxygen and hydrocarbon concentrations, hydrocarbon speciation, and DOC aging.

\section{ISSUES IN UREA SCR CONTROL}

It is important to realize that the SCR system is extremely good at converting $\mathrm{NO}_{x}$, provided it is operated under the right conditions. In particular, if the ammonia storage level on the catalyst is known, if the temperature is in a reasonable window, and if the feedgas $\mathrm{NO}_{x}$ concentration is known, it is quite easy to get good $\mathrm{NO}_{x}$ conversion. The capability of a control strategy can therefore not be evaluated by comparing $\mathrm{NO}_{x}$ conversion over an emissions cycle with known conditions. The difficult requirements of a urea SCR control strategy are to trade off $\mathrm{NO}_{x}$ conversion against ammonia slip, and to do so in the face of uncertainty. Among the major noise factors affecting system performance are:

- $\mathrm{NH}_{3}$ storage;

- $\mathrm{NO}_{x}$ concentration in the feed gas;

- urea input (injector uncertainty as well as urea concentration);

- drive cycle;

- sensor uncertainty. 


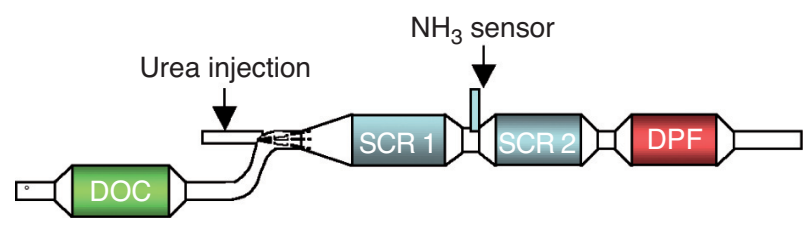

Figure 3

Two brick SCR system used as a case study.

We will demonstrate the challenges by simulations on a two brick SCR system, depicted in Figure 3. Unless explicitly specified otherwise, the results are from simulations on this system. Experimental results are used at times to reinforce some points. The first SCR has a volume of 7 liters, the second SCR has a volume of 3 liters. Each SCR is modeled as a one dimensional system, with 7 slices. The model is parametrized with chemical properties of a cupper zeolite based SCR catalyst. A detailed description of the model can be found in (Kim, 2007). The ammonia sensor between the two bricks will be used in Section 3.4 to study the design of observers.

The feedgas data used are from a Ford V8 engine operated over the EPA75 cycle. The intent behind the two brick system is firstly to ascertain the effect of SCR volume on $\mathrm{NO}_{x}$ conversion and ammonia slip. Subsequent simulations will show $\mathrm{NO}_{x}$ conversion and ammonia slip after the first and after the second brick. Secondly, the first brick can be considered as the control target, whereas the second brick can be interpreted as an ammonia slip control brick, used to reduce the ammonia slip caused by thermal excursions. In an optimized system, the bricks would have different washcoat formulations and or loadings, matched to their temperature exposure.

\subsection{Ammonia Storage}

$\mathrm{NO}_{x}$ conversion on SCR catalysts is to a large degree determined by the amount of stored ammonia, especially at low temperatures, see Figure 4. Figure 5 shows that SCR catalysts can store an enormous amount of ammonia. While we can control the increase in stored ammonia by injection of urea, we have no direct control action to decrease stored ammonia. Ammonia can only be released from the SCR by oxidation, thermal desorption or reaction with $\mathrm{NO}_{x}$. Oxidation cannot be directly controlled, thermal desorption results in large ammonia concentrations of the tailpipe exhaust gas, and with feedgas $\mathrm{NO}_{x}$ concentrations typical of 2010 diesel applications, it is hard to remove ammonia at high rates. A typical feedgas $\mathrm{NO}_{x}$ number is on the order of 0.5 to $1.0 \mathrm{~g} / \mathrm{mile}$. Typical ammonia storage is on the order of $1 \mathrm{~g} / \mathrm{L}$, so for a 10 liter catalyst, total ammonia stored is 10 grams. Assuming the standard reaction in Equation (2), 10 grams of ammonia reacts with $10 \times 46 / 17 \approx 25$ grams of $\mathrm{NO}_{x}$. It then takes between 12 and 25 miles to deplete the 10 grams of ammonia stored on the SCR. Thermal transients from normal driving operate on a much faster time scale than this. The challenge is to control ammonia storage to a level where it is high enough to achieve good $\mathrm{NO}_{x}$ conversion, but not so high that it will lead to ammonia slip under thermal transients. Due to the slow ammonia storage dynamics one must be careful to tune the ammonia storage solely to achieve good emissions performance over transient drive cycles. This typically leads to undesired behavior off-cycle. Figure 5 shows ammonia storage as function of temperature. Above temperatures of $550^{\circ} \mathrm{C}$ or so, storage decreases to negligible levels. The catalyst

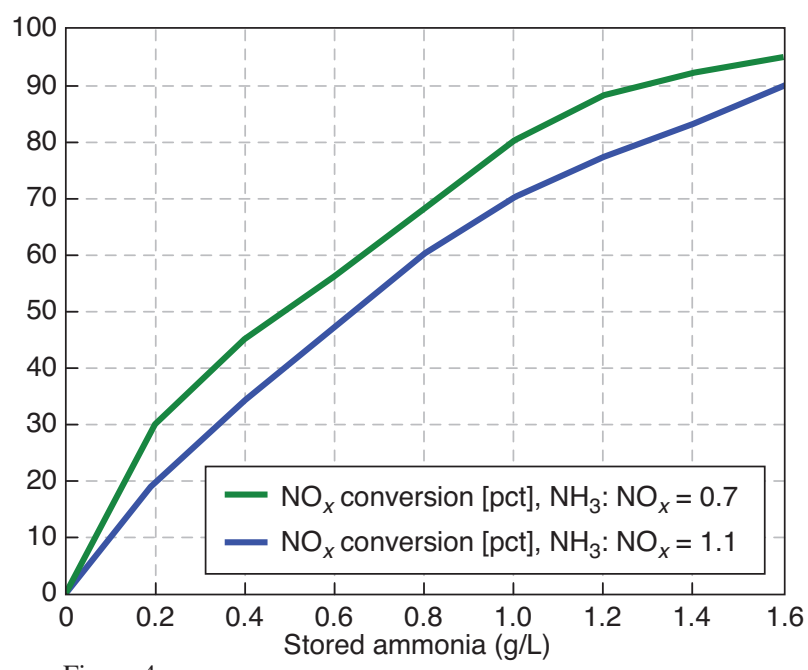

Figure 4

$\mathrm{NO}_{x}$ conversion efficiency (\%) as a function of stored ammonia in $\mathrm{g} / \mathrm{L}$, for different ammonia to $\mathrm{NO}_{x}$ ratios at $200^{\circ} \mathrm{C}$.

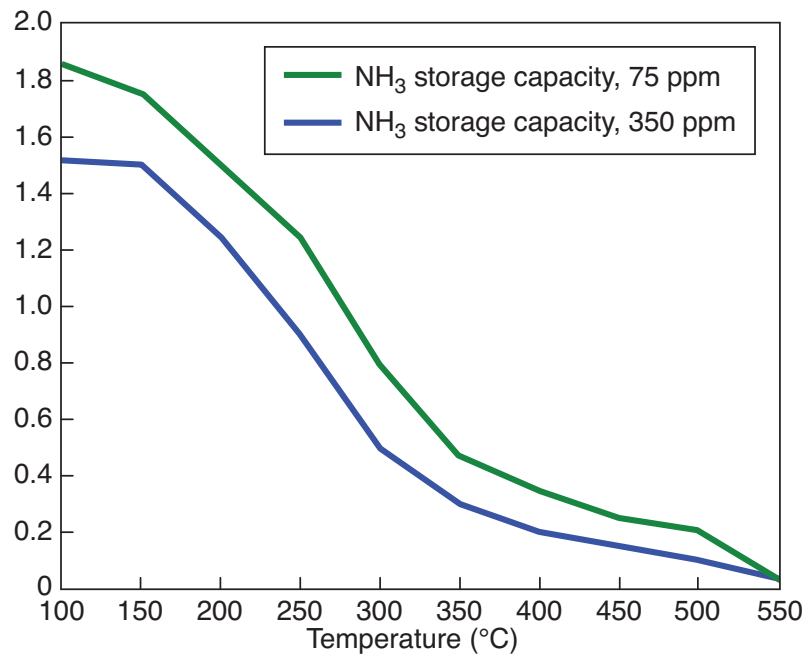

Figure 5

Ammonia storage in $\mathrm{g} / \mathrm{L}$ as a function of temperature, for different gas phase ammonia concentrations. 
can store more ammonia for higher gas phase ammonia concentrations. Figure 4 shows that $\mathrm{NO}_{x}$ conversion is to a large degree determined by ammonia storage, especially at lower temperatures, and that $\mathrm{NO}_{x}$ conversion increases to a lesser degree with increasing ratio of gas phase ammonia to $\mathrm{NO}_{x}$.

\subsection{Simple SCR Controllers}

The previous section showed the large contribution of ammonia storage to $\mathrm{NO}_{x}$ conversion. To set the stage we investigate the performance achieved when we rely exclusively on initial $\mathrm{NH}_{3}$ storage, without any urea injected during the drive cycle. Figure 6 shows that we can achieve reasonably good $\mathrm{NO}_{x}$ conversion (55\% for the 7 liter catalyst, $75 \%$ for the 10 liter catalyst), but at the expense of high ammonia slip (150-200 ppm).

A slightly more advanced control strategy is a feed forward only strategy, which injects urea proportionally to the $\mathrm{NO}_{x}$ going into the catalyst, to a 1:1 stoichiometric ratio.

Figure 7 shows that with this strategy and an initial ammonia storage of $0.08 \mathrm{~g} / \mathrm{L}$, we can achieve $88 \% \mathrm{NO}_{x}$ conversion, at the expense of $25 \mathrm{ppm}$ ammonia slip. Figure 8 shows that with $2.18 \mathrm{~g} / \mathrm{L}$ initial storage the $\mathrm{NO}_{x}$ conversion gets even better, 97\%, but this happens at the expense of a peak ammonia slip of $5981 \mathrm{ppm}$.

Figure 9 shows that the second hill in the EPA75 cycle is the condition most prone to ammonia slip, due to the fast thermal transient resulting from the steep acceleration in that part of the cycle.
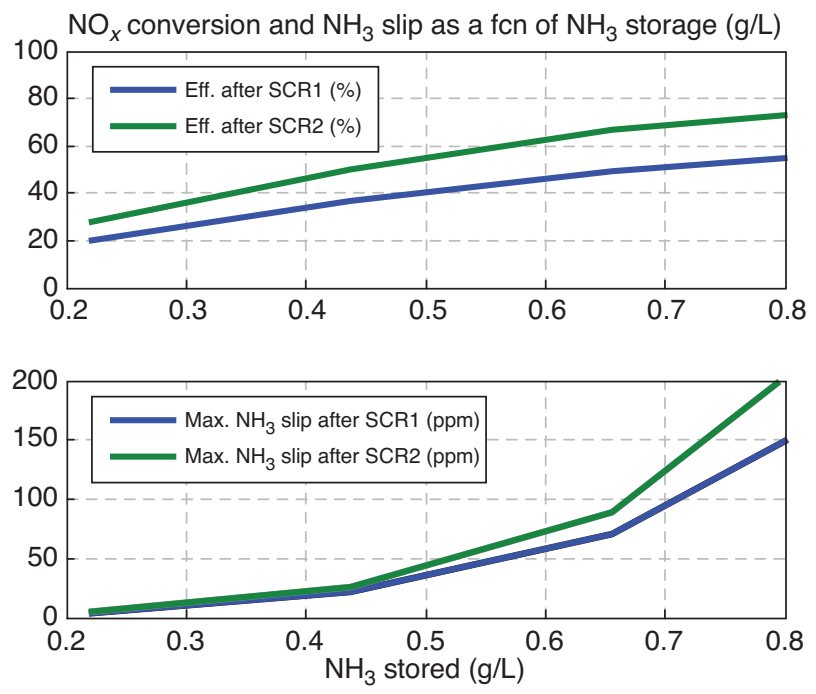

Figure 6

$\mathrm{NO}_{x}$ conversion and ammonia slip over an EPA75 cycle, for different initial storage levels, with 0 urea injection during the cycle.

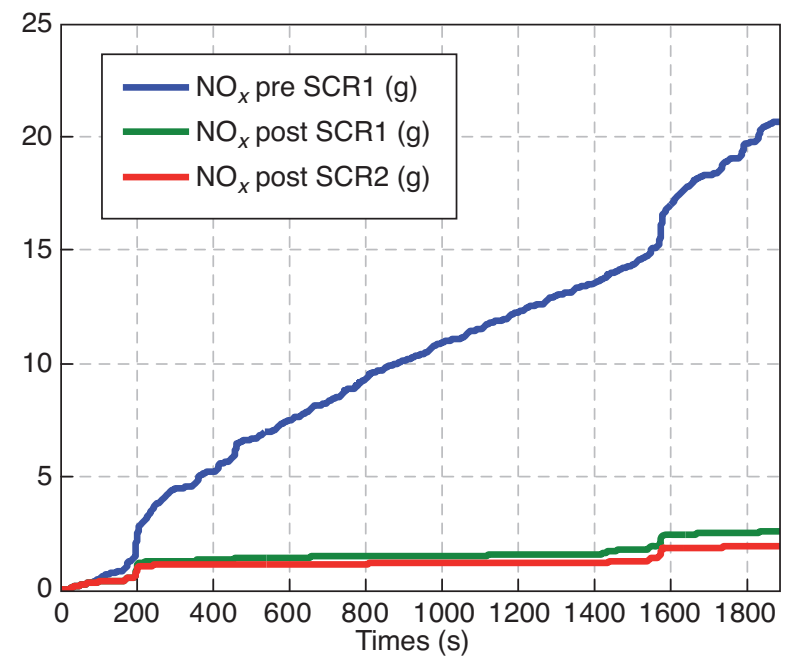

Figure 7

Integrated $\mathrm{NO}_{x}$ mass before, between and after the 2 SCR bricks from Figure 3. Initial $\mathrm{NH}_{3}$ storage is $0.08 \mathrm{~g} / \mathrm{L}$.

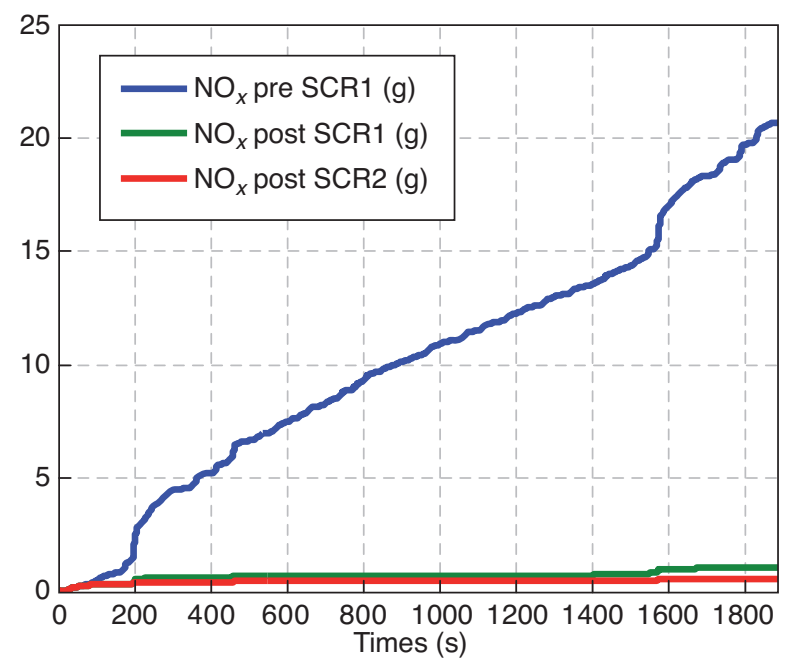

Figure 8

Integrated $\mathrm{NO}_{x}$ mass before, between and after the $2 \mathrm{SCR}$ bricks from Figure 3. Initial $\mathrm{NH}_{3}$ storage is $2.18 \mathrm{~g} / \mathrm{L}$.

Table 1 summarizes the trade off between $\mathrm{NO}_{x}$ conversion and ammonia slip for the strategies considered so far.

\section{TABLE 1}

$\mathrm{NO}_{x}$ conversion and ammonia slip for different urea injection strategies

\begin{tabular}{l|c|c|c}
\hline Strategy & Initial storage & No. conversion & $\mathrm{NH}_{3}$ slip \\
\hline & $\mathrm{g} / \mathrm{L}$ & $\mathrm{pct}$ & $\mathrm{ppm}$ \\
\hline No urea injection & 0.6 & 62 & 75 \\
\hline FF, low storage & 0.08 & 88 & 25 \\
\hline FF, high storage & 2.18 & 97 & 5981 \\
\hline
\end{tabular}




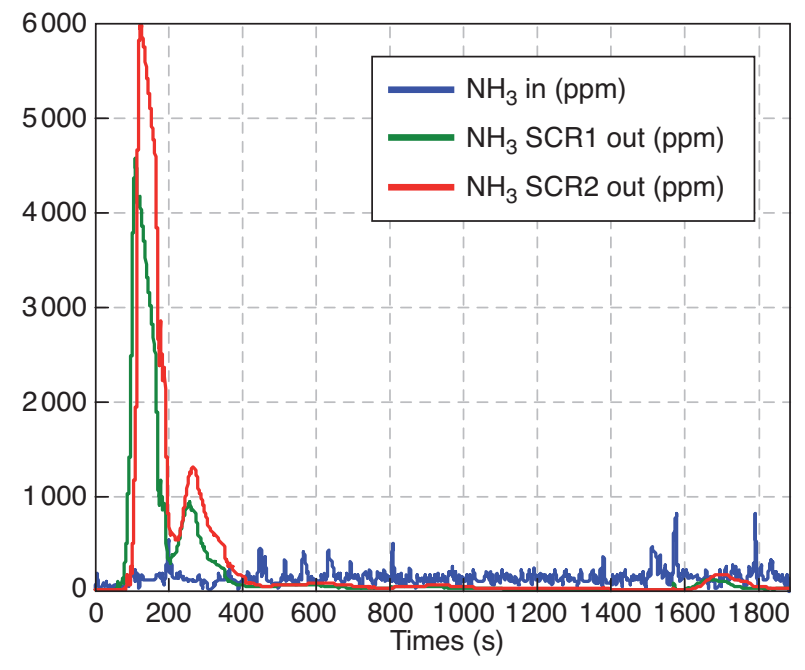

Figure 9

$\mathrm{NH}_{3}$ concentrations before, between and after the 2 SCR bricks from Figure 3, corresponding to the $\mathrm{NO}_{x}$ traces in Figure 8.

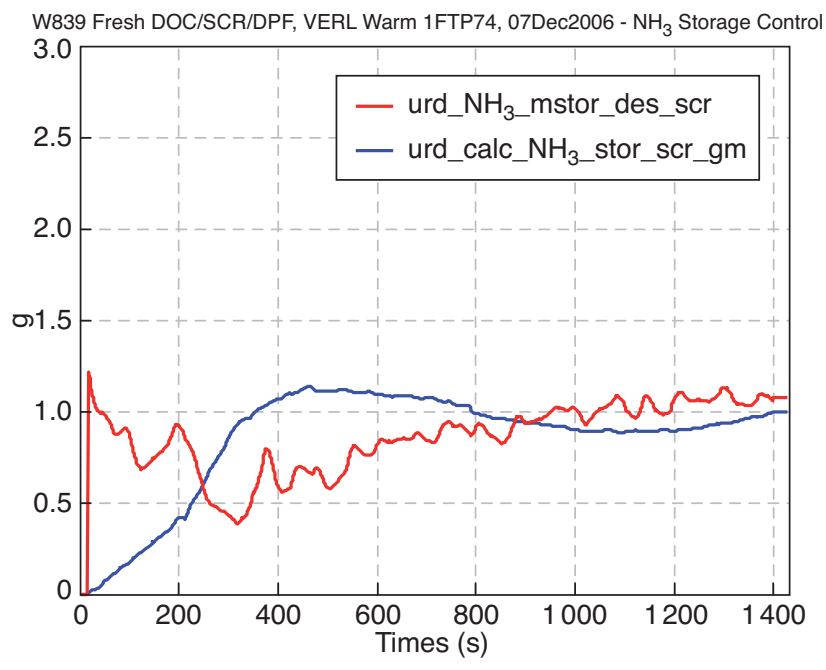

Figure 10

Performance of an ammonia storage controller. Experimental data. The red trace is desired storage, the blue line is achieved storage.

\subsection{Ammonia Storage Control}

In Upadhyay (2006) we presented the following simplified control oriented model of an SCR catalyst. The three states represent gas phase $\mathrm{NO}_{x}$ concentration, ammonia storage and gas phase ammonia concentration. The reaction rates $R_{x x x}$ $(x x x=$ ADS, DES, OX, RED) follow an Arrhenius equation with a strong temperature dependence, where ADS stands for adsorption, DES stands for desorption, OX stands for oxidation, RED stands for $\mathrm{NO}_{x}$ conversion. The control input $U$ is the ammonia from injected urea, the feedgas $\mathrm{NO}_{x}$ concentration is disturbance $d$ :

\section{See Equation (3)}

To give and example of storage control, Figure 10 shows the experimental performance of an ammonia storage controller based on this model, on a 5 liter catalyst over an EPA75 cycle. After the initial transient resulting from a start at zero ammonia storage, the controller can control the ammonia storage level to within around $0.1 \mathrm{~g} / \mathrm{L}$. This controller achieves between 92 and $98 \%$ conversion efficiency on repeated hot FTP74 cycles.

To study the issues involved in ammonia storage we simulate a storage controller on our simulation depicted in Figure 3. A simple PI controller on ammonia storage is added to the stoichometric feed forward controller of Section 3.2. In this simulation we control to the average ammonia storage of the different longitudinal slices in the first brick. Clearly, we cannot measure this quantity in a real system, but the assumption is useful to point out some fundamental limitations of storage control. Figure 11 shows that even if we know the ammonia storage level, the slow bandwidth of the storage dynamics force a oscillation around the storage target, with a period of around 20 minutes. This behaviour is qualitatively very similar to the experimental data in Figure 10.

It should be noted here that the stored ammonia is a calculated quantity, and as such the feed forward could be

$$
\left[\begin{array}{l}
\dot{C}_{\mathrm{NO}} \\
\dot{\theta} \\
\dot{C}_{\mathrm{NH}_{3}}
\end{array}\right]=\left[\begin{array}{l}
-\frac{C_{\mathrm{NO}}}{V_{c a t}}\left(\bar{R}_{R E D} \theta+F\right)+\frac{\bar{R}_{O X}}{V_{c a t}} \theta \\
-\frac{\theta}{\Theta_{S C}}\left(\bar{R}_{A D S} C_{\mathrm{NH}_{3}}+\bar{R}_{D E S}+\bar{R}_{R E D} C_{\mathrm{NO}}+\bar{R}_{O X}\right)+\frac{\bar{R}_{A D S}}{\Theta_{S C}} C_{\mathrm{NH}_{3}} \\
-\frac{C_{\mathrm{NH}_{3}}}{V_{c a t}}\left(\bar{R}_{A D S}(1-\theta)+F\right)+\frac{\bar{R}_{D E S}}{V_{c a t}} \theta
\end{array}\right]+\left[\begin{array}{l}
0 \\
0 \\
\frac{F}{V_{c a t}}
\end{array}\right] U+\left[\begin{array}{l}
\frac{F}{V_{c a t}} \\
0 \\
0
\end{array}\right] d
$$



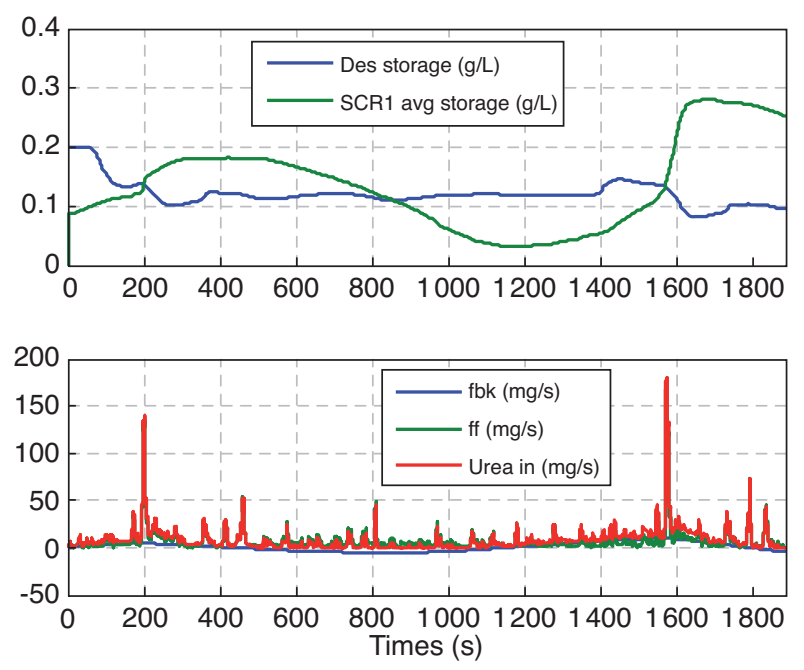

Figure 11

Ammonia storage control on the simulation system of Figure 3.

adjusted to exactly compensate for the disturbance caused by oxidation, ammonia desorption and $\mathrm{NO}_{x}$ conversion. There are issues with this approach:

- as noted before we can only control an increase in stored ammonia. If the desired storage is above the real (modelled) storage, we have no active control authority to drive the storage to the desired level;

- we only have approximate knowledge of the stored ammonia, and definitely only an inaccurate knowledge of the stored ammonia in each slice. Including the disturbance terms in the feed forward can easily lead to overcompensation;

- there is an advantage in keeping the excursions around the storage setpoint symmetric. Uncertainty in the model during overstored periods tends to be compensated by the same uncertainty during understored periods. Long term adaptive strategies that are superposed on ammonia storage feedback control count on a similar duration of overstored and understored periods to ascertain the effects of an adaptive adjustment.
This section demonstrated limitations of ammonia storage control if it can be measured. In real applications, of course, it cannot, and must be observed from sensor measurements.

\subsection{Observers for Ammonia Storage}

Figure 3 depicts an ammonia sensor between the two bricks. This configuration has been discussed in Herman (2009). The ammonia sensor can be used for storage feedback. The second brick is used to catch ammonia slipped from the first brick and increase overall $\mathrm{NO}_{x}$ conversion. We have little control over the thermal transients that drive ammonia desorption, so it is important to catch ammonia slip before it reaches the tail pipe. If the ammonia sensor were placed after the second brick, it would be too late to counteract ammonia slip by the time it was measured. In this section we study the use of the ammonia sensor to observe the stored ammonia in the first brick. We will investigate observers of different levels of complexity. First we can add an observer term to the three state model proposed in the beginning of Section 3:

\section{See Equation (4)}
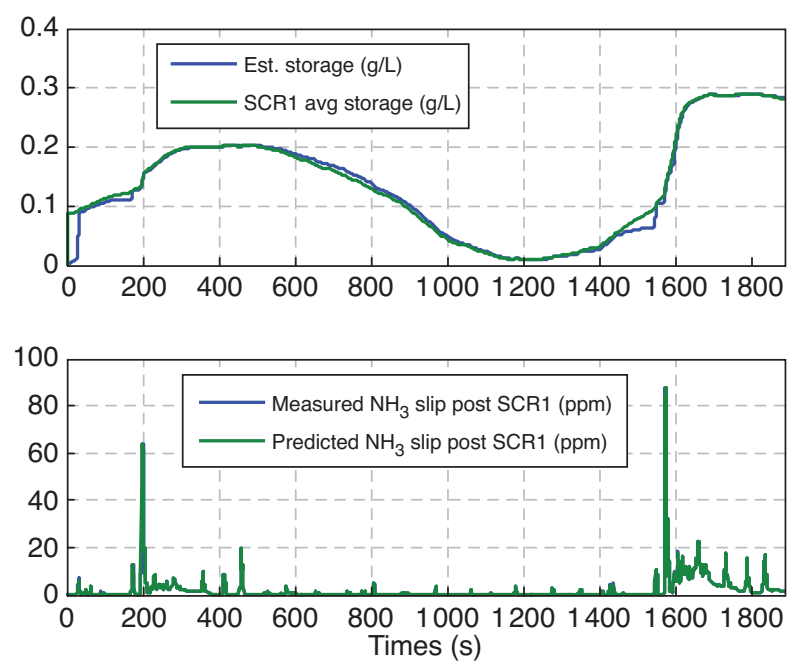

Figure 12

Observed and modelled storage, if the observer has access to the exact ammonia storage dynamics.

$$
\left[\begin{array}{l}
\dot{\hat{C}}_{\mathrm{NO}} \\
\dot{\hat{\theta}} \\
\dot{\hat{C}}_{\mathrm{NH}_{3}}
\end{array}\right]=\left[\begin{array}{l}
-\frac{\hat{C}_{\mathrm{NO}}}{V_{c a t}}\left(\bar{R}_{R E D} \hat{\theta}+F\right)+\frac{\bar{R}_{O X}}{V_{c a t}} \hat{\theta} \\
-\frac{\hat{\theta}}{\Theta_{S C}}\left(\bar{R}_{A D S} \hat{C}_{\mathrm{NH}_{3}}+\bar{R}_{D E S}+\bar{R}_{R E D} \hat{C}_{\mathrm{NO}}+\bar{R}_{O X}\right)+\frac{\bar{R}_{A D S}}{\Theta_{S C}} \hat{C}_{\mathrm{NH}_{3}} \\
-\frac{\hat{C}_{\mathrm{NH}}}{V_{c a t}}\left(\bar{R}_{A D S}(1-\hat{\theta})+F\right)+\frac{\bar{R}_{D E S}}{V_{c a t}} \hat{\theta}
\end{array}\right]+\left[\begin{array}{l}
0 \\
0 \\
\frac{F}{V_{c a t}}
\end{array}\right] U+\left[\begin{array}{l}
\frac{F}{V_{c a t}} \\
0 \\
0
\end{array}\right] d+\left[\begin{array}{l}
0 \\
K \\
0
\end{array}\right]\left(C_{\mathrm{NH}_{3}}-\widehat{C}_{\mathrm{NH}_{3}}\right)
$$




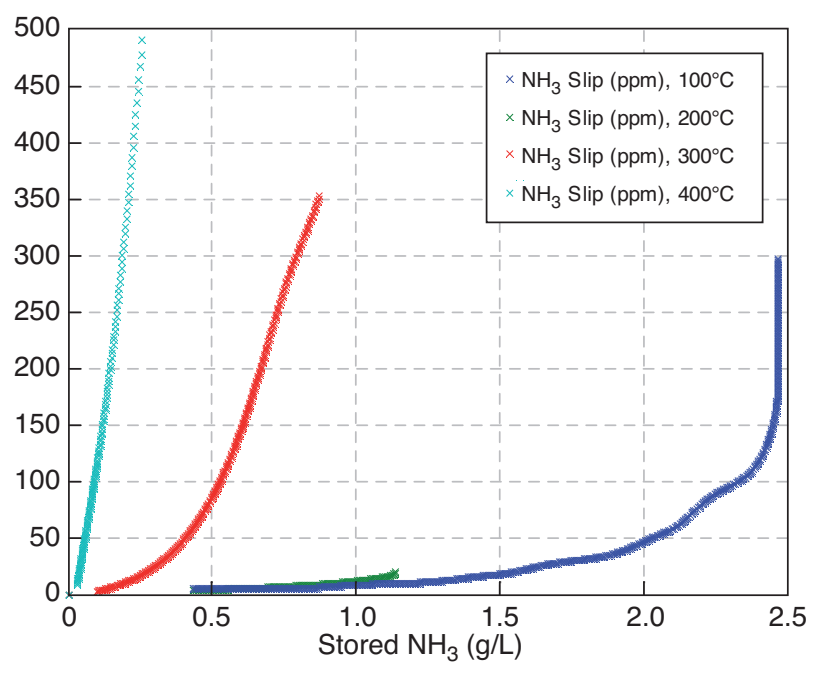

Figure 13

Simplified ammonia slip model for single state observer. This graph depicts the function $f(.,$.$) in Equation (5).$

Figure 12 shows that we can observe the stored ammonia with high accuracy if the observer has access to the full model.

To assess the performance of an observer, we need to evaluate it against modelling error and sensor uncertainty. To investigate the effect of modelling error, we propose the following simplified observer, that only relies on a single state for the ammonia storage dynamics:

$$
\begin{aligned}
& \dot{\hat{\theta}}=-\frac{\hat{\theta}}{\Theta_{S C}}\left(\bar{R}_{A D S} \hat{C}_{\mathrm{NH}_{3}}+\bar{R}_{D E S}+\bar{R}_{R E D} \hat{C}_{\mathrm{NO}}+\bar{R}_{O X}\right) \\
& +\frac{\bar{R}_{A D S}}{\Theta_{S C}} \hat{C}_{\mathrm{NH}_{3}}+K\left(C_{\mathrm{NH}_{3}}-\widehat{C}_{\mathrm{NH}_{3}}\right) \hat{C}_{\mathrm{NH}_{3}}=f(\hat{\theta}, T)
\end{aligned}
$$

The $\mathrm{NO}_{x}$ concentration $\hat{C}_{\mathrm{NO}}$ is solved by setting the first state equation of Equation (4) to 0, which is tantamount to assuming that the NO conversion happens on a much faster time scale than the ammonia storage and release. The ammonia slip function $f(\hat{\theta}, T)$ is modelled as shown in Figure 13. These curves were generated for an inlet NO concentration of $300 \mathrm{pm}$, an inlet $\mathrm{NO}_{2}$ concentration of $0 \mathrm{ppm}$, an inlet ammonia concentration of $300 \mathrm{ppm}$, and at $300 \mathrm{~kg} / \mathrm{h}$ mass flow, for 4 different temperatures between 100 and $400^{\circ} \mathrm{C}$. This Figure shows that for very high temperatures, ammonia slip occurs even at low storage levels, whereas at low temperatures, there is very little ammonia slip even for high storage levels. The EPA75 emissions cycle operates at lower temperatures, below $300^{\circ} \mathrm{C}$, where there is a weak correlation between ammonia storage and ammonia slip.

Figure 14 shows that the weak correlation between storage and slip results in a systematic underestimation of ammonia
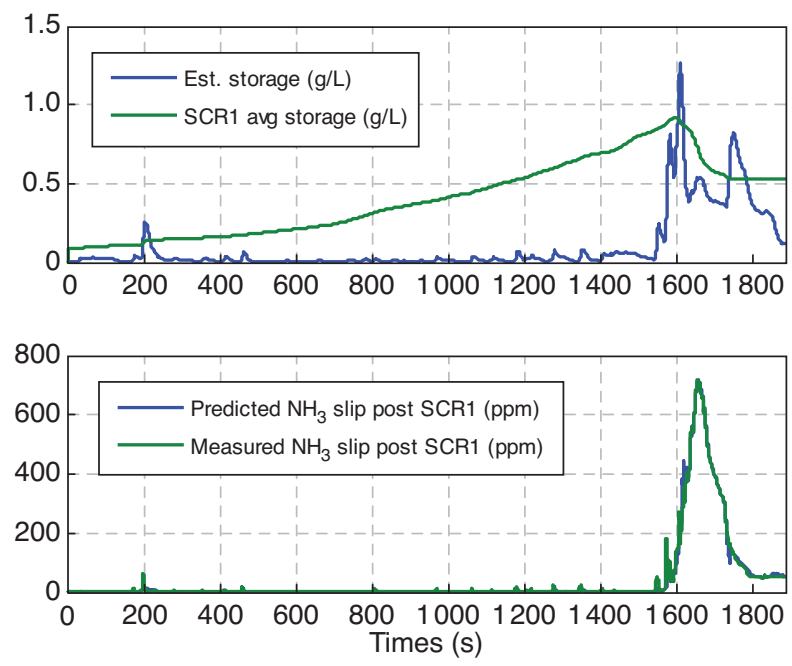

Figure 14

Estimated and real $\mathrm{NH}_{3}$ storage. Predicted and measured $\mathrm{NH}_{3}$ slip after the first brick. Around $1500 \mathrm{~s}$, the feedback action results in significant $\mathrm{NH}_{3}$ slip and the observer can catch up with the real storage.

storage, until we get substantial ammonia slip in bag 3. As soon as ammonia slip reaches significant levels, the observer can catch up and takes values of similar order of magnitude as the real storage. Note that the observed and measured ammonia slip levels are very close, due to the high gains in the observer and the monotonic relation between ammonia storage and slip. This is not really a sign of good performance of the observer. Note that due to underestimation of ammonia storage, the PI controlled on storage increases storage level, until ammonia slip occurs in bag 3 . The simulation shown in Figure 14 achieved a $\mathrm{NO}_{x}$ conversion of $90.2 \%$ at the expense of an ammonia slip level of 212 ppm after the second brick. Note that Figure 14 only shows the ammonia slip after the first brick, which is substantially higher than that observed after the second brick.

The observer performance can be improved by decreasing the gain, and by intentionally overestimating the ammonia slip function $f(\hat{\theta}, T)$ in Equation (5). This amounts to shifting the curves in Figure 13 up. Figure 15 shows the improved performance of the ammonia storage observer resulting from these measures. The slip after the first brick is less than in Figure 14, the $\mathrm{NO}_{x}$ conversion after the second brick is $90.8 \%$, and the ammonia slip is reduced from 212 to $36 \mathrm{ppm}$.

Next we investigate the effect of a bias in the ammonia sensor. Figure 16 shows the ammonia slip and $\mathrm{NO}_{x}$ conversion as a function of the multiplicative sensor error. It is seen that since a multiplicative error still correctly predicts the onset of ammonia slip, the observer is quite robust against multiplicative errors. Figure 17 shows the ammonia slip and $\mathrm{NO}_{x}$ conversion as a function of the additive sensor error. 

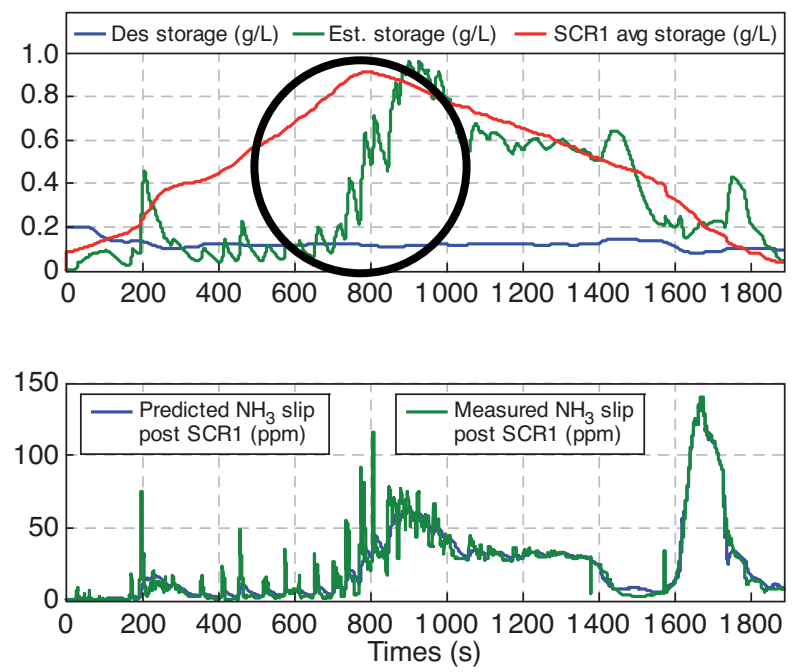

Figure 15

Top: estimated and real $\mathrm{NH}_{3}$ storage. Bottom: predicted and measured $\mathrm{NH}_{3}$ slip after the first brick. Compared to Figure 14 , this simulation uses lower gain, and overestimates the ammonia slip.

$\mathrm{NO}_{x}$ conversion and $\mathrm{NH}_{3}$ slip, as a fen of $\mathrm{NH}_{3}$ sensor gain error

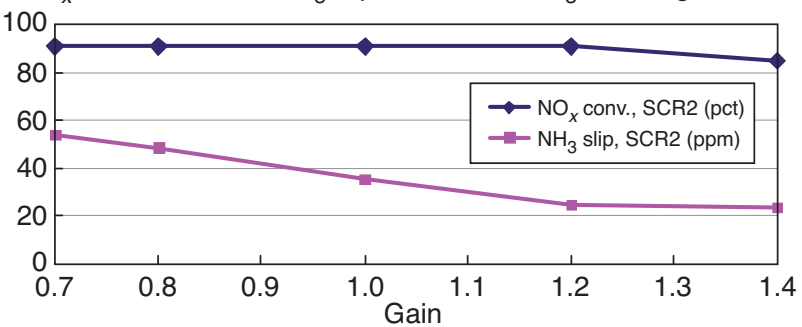

Figure 16

$\mathrm{NO}_{x}$ conversion and ammonia slip as a function of multiplicative sensor error.

$\mathrm{NO}_{x}$ conversion and $\mathrm{NH}_{3}$ slip, as a fcn of $\mathrm{NH}_{3}$ sensor offset error

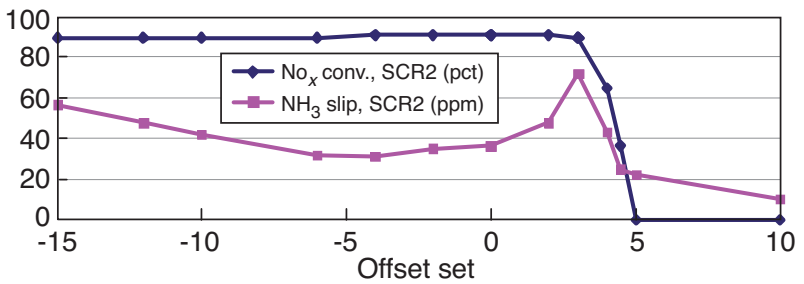

Figure 17

$\mathrm{NO}_{x}$ conversion and ammonia slip as a function of additive sensor error.

A positive additive error causes the observer to overestimate ammonia storage, and hence the controller to reduce urea injection. Specifically, if the sensor bias is greater than the ammonia slip corresponding to the desired storage level, the storage controller will completely turn off urea injection and result in zero $\mathrm{NO}_{x}$ conversion and ammonia slip for larger additive errors.

The above account points out a fundamental limitation in observer design for this system. While we can take action to achieve robustness against multiplicative uncertainty, both in modelling and sensor, it is hard to achieve robustness against additive uncertainty, both in modelling and sensor, especially if this uncertainty corresponds to a magnitude of the desired level of ammonia storage.

\section{$4 \mathrm{NO}_{x}$ SENSORS}

The previous section discussed the use of an ammonia sensor for observation of the ammonia storage. Since ammonia sensors are not available for large volume applications in 2010, current US diesel applications need to rely on a $\mathrm{NO}_{x}$ sensor. In this section we will discuss some tools to use a $\mathrm{NO}_{x}$ sensor to detect ammonia slip. Since $\mathrm{NO}_{x}$ sensors are heated to above $600^{\circ} \mathrm{C}$, any ammonia in the exhaust gas will be oxidized on the sensor element, and converted to $\mathrm{NO}_{x}$. Hence $\mathrm{NO}_{x}$ sensors are also sensitive to ammonia. The sensitivity depends on the protection tube design, the exhaust temperature, and the microstructure of the diffusion barrier in the sensor. Since the $\mathrm{NO}_{x}$ sensor is not designed to sense ammonia, the sensitivity to ammonia shows a large variability from part to part and over life time.

The $\mathrm{NO}_{x}$ sensor is sensitive to both $\mathrm{NO}$ and $\mathrm{NO}_{2}$, with different gains. $\mathrm{NO}_{2}$ is a larger molecule, hence experiences a larger resistance to transport through the diffusion barrier. Additionally $\mathrm{NO}_{2}$ accounts for two oxygen atoms once it is dissociated in the sensing chamber. Depending on the sensor details the sensitivity to $\mathrm{NO}_{2}$ can be between $70 \%$ and $130 \%$ of that to NO.

\subsection{Measuring Ammonia with a $\mathrm{NO}_{x}$ Sensor}

Since the $\mathrm{NO}_{x}$ sensor is sensitive to both ammonia and $\mathrm{NO}_{x}$, one cannot a priori determine which combination of these species causes a nonzero sensor reading. We propose a correlation scheme with the urea injection input to ascertain which species is registered, (Van Nieuwstadt, 2003). Suppose we are running in steady state conditions, where the SCR catalyst is in a regime of good $\mathrm{NO}_{x}$ conversion. If we increase the urea injection and see a decrease in output, we can infer that we were sensing $\mathrm{NO}_{\mathrm{x}}$, since the increased ammonia in the feedgas reacted with $\mathrm{NO}_{x}$ and reduced the sensor reading. If on the other hand we see an increase in sensor output when we increase urea input, we can infer that we were sensing ammonia, since the extra ammonia in the feedgas passed through the SCR and was sensed by the $\mathrm{NO}_{x}$ sensor. By correlating the change in input $u_{h p}$ to the change in output $y_{h p}$, we can construct a metric $M$ that is positive when we measure ammonia, and negative when we measure $\mathrm{NO}_{x}$. 


$$
M=\int u_{h p} y_{h p} d t
$$

This metric can be enhanced by including the SCR reaction dynamics and correlating the measured change in output $y_{\text {meas }, h p}$ to a modelled change in output $y_{\text {mod,hp }}$ :

$$
M=\int y_{\text {mod }, h p} y_{\text {meas }, h p} d t
$$

The performance of this metric is shown in Figure 18. The engine is operated in steady state, and a multiplicative square wave perturbation is applied to the urea injection quantity, which is biased low by $30 \%$. It can be seen that the metric $M$ increases and then reaches steady state. After application of an appropriate scaling map, the metric value can be mapped to correct the injector by $+30 \%$. Note the slow time scale of this data set. It takes about half an hour to learn this $30 \%$ bias. This is again due to the slow storage dynamics of the SCR when operated at temperatures where conversion efficiency is good.

We investigate the system bandwidth by simulating a sinusoidal urea injection perturbation and measuring the ratio of the output amplitude to the input amplitude. Figure 19 shows that at $300^{\circ} \mathrm{C}$, the system gain is below 0.01 for frequencies above $0.03 \mathrm{~Hz}$ (that is a period of 30 seconds). As expected, the system gain is lower for the 10 liter catalyst (the two bricks in Fig. 3) than for the 7 liter catalyst (the first brick only). Since we cannot expect the SCR catalyst to stay in steady state optimal conversion conditions for several periods, the applicability of this algorithm is deemed limited at lower temperatures. Figure 20 shows that the system gain increases to order of magnitude 1 at $560^{\circ} \mathrm{C}$. At higher temperatures we have seen that the ammonia storage capacity decreases, and hence the correlation algorithm in Equations $(6,7)$ could work.

At lower temperatures, where the SCR normally operates, we need to resort to more complex methods of averaging over a long horizon and correlating with the output to determine whether we are slipping ammonia or $\mathrm{NO}_{x}$.

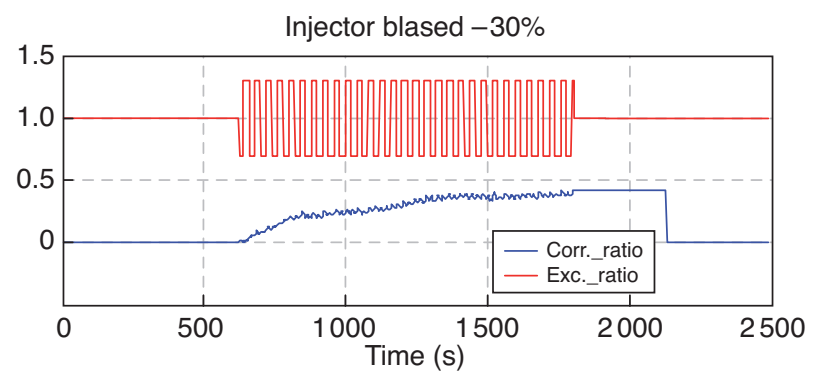

Figure 18

Input excitation and correlation metric $M$, for an injector bias of $-30 \%$.

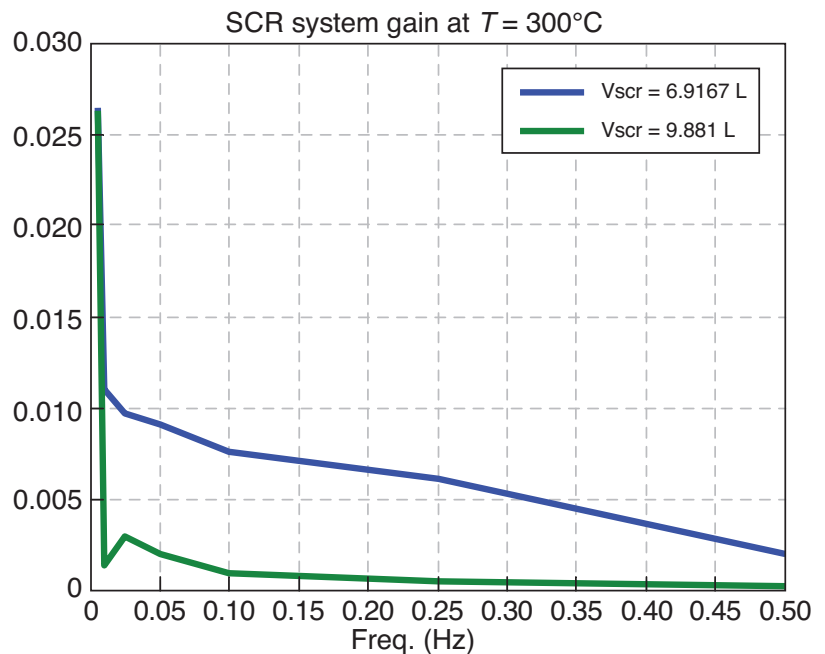

Figure 19

Simulated Bode plot for the SCR catalyst at $300^{\circ} \mathrm{C}$, for two different catalyst volumes.

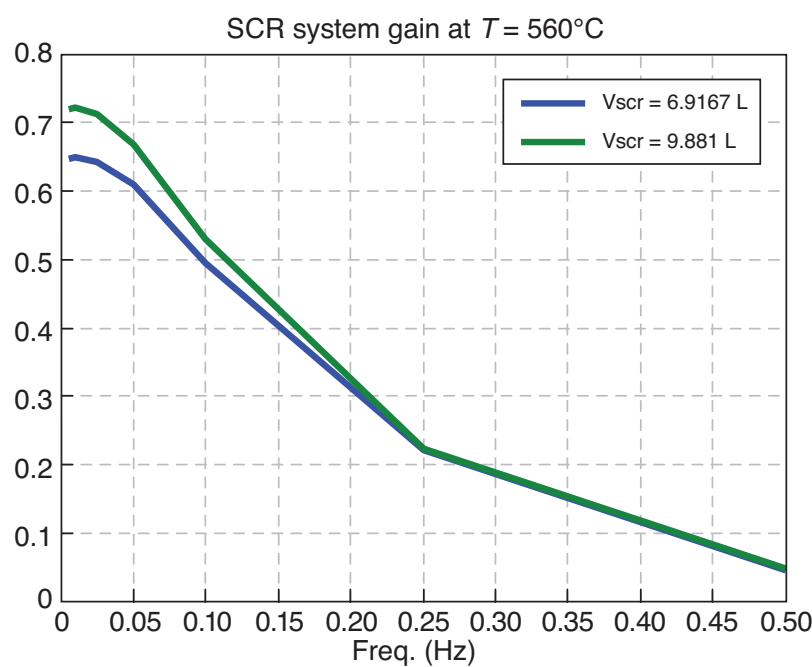

Figure 20

Simulated Bode plot for the SCR catalyst at $560^{\circ} \mathrm{C}$, for two different catalyst volumes.

\section{CONCLUSIONS AND OUTLOOK}

This paper does not claim to present the best possible control strategy for urea SCR systems. It does not advertise any particular control design methodology. Rather it points out some fundamental issues that need to be understood to design and evaluate a urea SCR control strategy. Key is to understand that it is easy to get good $\mathrm{NO}_{x}$ conversion with known $\mathrm{NO}_{x}$ and urea input, and initial storage. Major challenges are the uncertainty in these parameters, especially in the face of part to part variability and aging over lifetime. 
We show that ammonia sensors can be used to observe ammonia storage, but that conventional observer designs are sensitive to sensor offset.

We show that $\mathrm{NO}_{x}$ sensors can be used in conjunction with a correlation with the injected urea, to differentiate $\mathrm{NO}_{x}$ from ammonia at the tail pipe.

One recurring theme is the slow storage dynamics of the SCR at normal operating temperatures. While high ammonia storage is beneficial for $\mathrm{NO}_{x}$ conversion, especially at low temperatures, it makes controlling the SCR system quite complicated. It is the root cause for the slow oscillations when controlling ammonia storage. It is the reason that ammonia sensor based observers are sensitive to sensor offset. It is also the reason one cannot employ a simple input-output correlation with input excitation. At this point we are not aware of any developments that would allow similar $\mathrm{NO}_{x}$ conversion with substantially lower ammonia storage robustly over all drive cycles and varying operating conditions.

\section{ACKNOWLEDGMENTS}

We thank P. Laing, J. Kim and the rest of their team for the development of the SCR model used for all simulations in this paper. We thank C. Lambert, G. Cavataio and the rest of their team for the gas bench data on SCR catalysts. We thank A. Brahma for the synthesis of the two-brick model. Finally, E. Serban provided engine experimental data used in this paper.

\section{REFERENCES}

EPA (2009) Light-Duty Vehicle and Light-Duty Truck - Clean Fuel Fleet Exhaust Emission Standards, http://www.epa.gov/otaq/standards/light-duty/ld-cff.htm.

Fulks G., Fisher G., Rahmoeller K., Wu M.C., D’Herde E., Tan J. (2009) A Review of solid materials as alternative ammonia sources for Lean $\mathrm{NO}_{x}$ Reduction with SCR, SAE paper 2009-01-0907.

Herman A., Wu M., Cabush D., Shost M. (2009) Model based control of SCR dosing and OBD strategies with feedback from $\mathrm{NH}_{3}$ sensors, SAE paper 2009-010911.

VW Jetta (2009) Volkswagen Jetta TDi Test Drive: Clean Diesel's 50 MPG Meets Prius-Humbling Thrust, Popular Mechanics, http://www.popularmechanics.com/blogs/automotive_news/423558 6.html.

Kim J.Y., Cavataio G., Patterson J., Laing P.M., Lambert C.L. (2007) Laboratory Studies and Mathematical Modeling of Urea SCR Catalyst Performance, SAE paper 2007-01-1573.

Upadhyay D., Van Nieuwstadt M.J. (2006) Model Based Analysis and Control Design of a Urea-SCR de $\mathrm{NO}_{x}$ Aftertreatment System, J. Dyn. Syst. Meas. Control 128, 737-741.

Van Nieuwstadt M. (2003) US patent 6,546,720. 